\title{
Transition metal-substituted Keggin-type polyoxometalates as catalysts for adipic acid production
}

\author{
Sihem Mouanni ${ }^{1} \cdot$ Dahbia Amitouche $^{1,2} \cdot$ Tassadit Mazari $^{1,2} \cdot$ Cherifa Rabia $^{1}$
}

Received: 29 October 2018 / Accepted: 15 March 2019 / Published online: 9 April 2019

(c) The Author(s) 2019

\begin{abstract}
The adipic acid (AA) production was carried out in two stages: oxidation of cyclohexanone (-one) by Keggin-type polyoxometalate (POM), followed by oxidation of this latter by hydrogen peroxide. The process lasts $20 \mathrm{~h}$ and the temperature is maintained at $90{ }^{\circ} \mathrm{C}$. AA is then recovered by cold crystallization $\left(4^{\circ} \mathrm{C}\right)$. The POMs have as formula $\mathrm{HMPMo}_{12} \mathrm{O}_{40}(\mathrm{M}: \mathrm{Co}$, $\mathrm{Ni}, \mathrm{Mn}, \mathrm{Cu}$ or $\mathrm{Zn}$ ). The materials were characterized by FT-IR and UV-Vis spectroscopies and by thermogravimetric analysis. The purity of adipic acid was confirmed by FT-IR and ${ }^{13} \mathrm{C}$ and ${ }^{1} \mathrm{H}$ NMR analysis. The effects of POM composition, catalyst/-one molar ratio and the cyclohexanol addition to -one on adipic acid yield were examined. The whole catalysts were found to be effective toward cyclohexanone oxidation and the highest yield (53\%) was obtained with $\mathrm{HZnPMo}_{12} \mathrm{O}_{40}$ system for a catalyst/-one molar ratio of $1.89 \times 10^{-3}$. The alcohol addition to -one has a negative effect on adipic acid formation.
\end{abstract}

Keywords Keggin-type heteropoly salts $\cdot$ Oxidation $\cdot$ Hydrogen peroxide $\cdot$ Cyclohexanone $\cdot$ Adipic acid

\section{Introduction}

Adipic acid (AA) is a raw material for the production of polyamides, particularly nylon 6-6, polyesters and polyurethanes and food additives [7, 17]. AA is obtained industrially from oxidation of a mixture of cyclohexanone and cyclohexanol (noted KA oil) by nitric acid. This process has several disadvantages such as the corrosion phenomenon and release of nitrogen oxides coming from nitric acid reduction. Among these gases, $\mathrm{N}_{2} \mathrm{O}$ that represents $300 \mathrm{~kg} \mathrm{~N} \mathrm{~N}_{2} \mathrm{O} /$ ton of AA, is the most dangerous. In addition to its strong greenhouse effect and long residence time in the atmosphere, it participates in ozone layer destruction [22, 34]. The development of an environmentally friendly process is one of the most difficult research tasks to achieve.

Among used green oxidants, hydrogen peroxide $\left(\mathrm{H}_{2} \mathrm{O}_{2}\right)$ seems to be the most attractive compared to oxygen molecules and air [5, 8, 33, 35]. Effectively, in addition to being

Tassadit Mazari

tassa2002dz@yahoo.fr; tassa2002dz@gmail.com

1 Laboratoire de Chimie du Gaz Naturel, Faculté de Chimie, USTHB, BP32, El-Alia, Bab-Ezzouar, 16111 Algier, Algeria

2 Laboratoire de Chimie Appliquée et Génie Chimique, Université Mouloud Mammeri, Tizi-Ouzou (UMMTO), Algier, Algeria easy to handle, it is known for its clean environment because of its reduction that leads only to water formation.

In organic synthesis, $\mathrm{H}_{2} \mathrm{O}_{2}$ is widely used in alkene epoxidation reactions $[12,13,18]$ and Baeyer-Villiger oxidation reactions of cyclic ketones and aldehydes [37, 38, $40,41]$. In the case of AA synthesis, $\mathrm{H}_{2} \mathrm{O}_{2}$ was used in the presence of different catalysts such as $\mu_{3}$-oxo-bridged $\mathrm{Co} /$ $\mathrm{Mn}$ cluster complexes $\mathrm{CoMn}_{2}(\mathrm{O})[9],\left[\mathrm{Mn}^{\mathrm{III}} \mathrm{T}(p-\mathrm{Cl}) \mathrm{PP}\right]$ $\mathrm{Cl}$ [23], $N$-hydroxyphthalimide combined with $\mathrm{Mn}(\mathrm{acac})_{2}$ or $\mathrm{Co}(\mathrm{OAc})_{2}$ [19], $\beta-\left\{\left[\mathrm{H}_{3} \mathrm{NC}\left(\mathrm{CH}_{2} \mathrm{O}\right)_{3}\right]_{2} \mathrm{MnMo}_{6} \mathrm{O}_{18}\right\}$ [24], $\left[\mathrm{CoPM}_{11} \mathrm{O}_{39}\right]^{5-}$ and $\left[\mathrm{NiPM}_{11} \mathrm{O}_{39}\right]^{5-}[1]$. In these processes, $\mathrm{H}_{2} \mathrm{O}_{2}$ was added to the reaction mixture at the same time as the substrate (cyclohexene, cyclohexanone or cyclohexanol) and catalyst.

In our previous works, AA synthesis was carried out in two stages, using the Nomiya process [32], in the presence of Keggin or Dawson polyoxometalate of formulas $\mathrm{M}_{x} \mathrm{PMo}_{12} \mathrm{O}_{40}(\mathrm{M}: \mathrm{Fe}, \mathrm{Ni}, \mathrm{Co}$ and $x: 1$ or 1.5) [26], $\mathrm{H}_{3-2 x} \mathrm{Co}_{x} \mathrm{PMo}_{12} \mathrm{O}_{40}(x: 0-1.5)$ [4] $\left(\mathrm{NH}_{4}\right)_{3-2 x} \mathrm{Ni}_{x} \mathrm{PMo}_{12} \mathrm{O}_{40}$ $(x: 0.25-1.5)$ [39] and $\left(\mathrm{NH}_{4}\right)_{x} \mathrm{~A}_{y} \mathrm{PMo}_{12} \mathrm{O}_{40}\left(\mathrm{~A}^{n+}=\mathrm{Sb}^{3+}\right.$, $\mathrm{Bi}^{3+}$ or $\mathrm{Sn}^{2+}$ ) [31]. In the first step, the reaction mixture consists of a substrate (cyclohexanone or cyclohexanol) and POM. The role of the POM is to oxidize the substrate, which results in a color change from yellow (characteristic color of the oxidized POM) to blue (characteristic color of the reduced POM). Then,

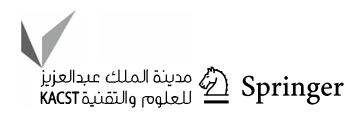


hydrogen peroxide is added in the second step. In the latter case, $\mathrm{H}_{2} \mathrm{O}_{2}$ reacts as an oxidant to restore the POM and as a peroxide to form peroxo species with the POM. These peroxo species were reported by several authors as the active species in the formation of oxygenated compounds. They were evidenced by multinuclear NMR spectroscopies in the cases of $\mathrm{H}_{3} \mathrm{PW}_{12} \mathrm{O}_{40}$ as $\left\{\mathrm{PO}_{4}\left[\mathrm{WO}\left(\mathrm{O}_{2}\right)_{2}\right]_{4}\right\}^{3-}$ and $\left\{\mathrm{PO}_{4}\left[\mathrm{WO}\left(\mathrm{O}_{2}\right)_{2}\right]_{2}\right\}^{2-}[14,16]$ and $\mathrm{H}_{3} \mathrm{PMo}_{12} \mathrm{O}_{40}$ as $\left\{\mathrm{PO}_{4}\left[\mathrm{MoO}\left(\mathrm{O}_{2}\right)_{2}\right]_{4}\right\}^{3-},\left\{\mathrm{PMo}_{3} \mathrm{O}_{\mathrm{m}}\right\}^{n-}$ and $\left\{\mathrm{PO}_{4}\left[\mathrm{MoO}\left(\mathrm{O}_{2}\right)_{2}\right]_{2}\right\}^{2-}[2,21]$.

In these different series of POMs, it was observed that those which contain metal (M) counter-ions having several oxidation states such as $\mathrm{Co}, \mathrm{Mn}, \mathrm{Sn}$ and $\mathrm{Sb}$ led to better AA yields. This has been attributed to the presence of several redox couples as $\mathrm{Co}(\mathrm{III}) / \mathrm{Co}(\mathrm{II}), \mathrm{Mn}(\mathrm{IV}) /$ $\mathrm{Mn}(\mathrm{II}), \mathrm{Sn}(\mathrm{IV}) / \mathrm{Sn}(\mathrm{II})$ and $\mathrm{Sb}(\mathrm{V}) / \mathrm{Sb}(\mathrm{III})$, formed during the POM. A redox reaction occurs in situ between Mo(VI) and M(II). On the other hand, in recent work, it has been shown that the proton presence in the POM allows the activation of cyclohexanone by keto-enolic tautomerization, before its oxidation into more oxygenated compounds [2].

In this context and to understand the influence of the metal nature on adipic acid formation, we tested a series of substituted POMs by introducing both single metal atom with an oxidation state of 2 and single proton as counter-ion of the $\left[\mathrm{PMo}_{12} \mathrm{O}_{40}\right]^{3-}$ Keggin anion. The choice was made on $\mathrm{Co}$ and $\mathrm{Mn}$ that have several oxidation states, $\mathrm{Ni}$ that has only one oxidation state (II) and $\mathrm{Cu}$ that has several oxidation states, but it cannot be reduced from $\mathrm{Cu}$ (II) to $\mathrm{Cu}(\mathrm{I})$ and $\mathrm{Zn}$ as a non-transition metal with one oxidation state (II). Their formula is $\mathrm{HMPMo}_{12} \mathrm{O}_{40}$. They were characterized by FT-IR and UV-Vis spectroscopies. The catalytic cyclohexanone oxidation to adipic acid was carried out in the homogenous phase at $90{ }^{\circ} \mathrm{C}$ using $\mathrm{H}_{2} \mathrm{O}_{2}(30 \%)$. The effects of the catalyst/-one molar ratio and that of the alcohol addition (ratio -one/-ol) on adipic acid yield were studied. The purity of adipic acid was verified by FT-IR, ${ }^{13} \mathrm{C}$ and ${ }^{1} \mathrm{H}$ NMR analysis.

\section{Experimental}

\section{Material synthesis}

$\mathrm{HMPMo}_{12} \mathrm{O}_{40}$ heteropoly salts were prepared using a cationic exchange method $[4,26,39]$. In the first step, $\mathrm{H}_{3-2 x} \mathrm{Ba}_{x} \mathrm{PMo}_{12} \mathrm{O}_{40}$, substituted salt was prepared by $\mathrm{Ba}(\mathrm{OH})_{2}$ addition to an aqueous solution of $\mathrm{H}_{3} \mathrm{PMo}_{12} \mathrm{O}_{40}$ in stoichiometric ratios, according to the RXN. (1) To avoid the Keggin anion decomposition, it is necessary to maintain $\mathrm{pH}<2$, by gradual addition of $\mathrm{Ba}(\mathrm{OH})_{2}$. The second step consists in the substitution of $\mathrm{Ba}^{2+}$ ions by the transition metal $\mathrm{M}^{2+}$ (M:Co, $\mathrm{Ni}, \mathrm{Mn}, \mathrm{Cu}$ or $\mathrm{Zn}$ ) using $\mathrm{MSO}_{4}$ according to the RXN. (2) After total $\mathrm{BaSO}_{4}$ precipitation, the filtrate was dried at $50{ }^{\circ} \mathrm{C}$ under vacuum and $\mathrm{HMPMo}_{12} \mathrm{O}_{40}$ recovered in the form of a powder:

$$
\begin{aligned}
& \mathrm{H}_{3} \mathrm{PMo}_{12} \mathrm{O}_{40}+\mathrm{Ba}(\mathrm{OH})_{2} \rightarrow \mathrm{HBaPMo}_{12} \mathrm{O}_{40}+2 \mathrm{H}_{2} \mathrm{O} \mathrm{RXN}(1) \\
& \mathrm{HBaPMo}_{12} \mathrm{O}_{40}+\mathrm{MSO}_{4} \rightarrow \mathrm{HMPMo}_{12} \mathrm{O}_{40}+\mathrm{BaSO}_{4} \downarrow \mathrm{RXN}(2)
\end{aligned}
$$

The $\mathrm{M}$ presence confirmation was realized using the complexation tests shown in Table 1.

\section{Characterization}

The FT-IR spectra recording of salts was carried out on a Fourier Transform Nicolet-Magna 550 IR spectrometer. The samples are ground in the $\mathrm{KBr}(2 \mathrm{mg}$ of sample per $200 \mathrm{mg}$ of $\mathrm{KBr}$ ) and then pressed in the form of pellets. The spectra were treated by Omnic 8.1 software.

UV-Vis spectra of samples were recorded between 100 and $1000 \mathrm{~nm}$ on a Shimadzu UV-1601 PC spectrometer.

Thermal analysis was performed between room temperature and $600{ }^{\circ} \mathrm{C}$, under air flow with a heating rate of $5{ }^{\circ} \mathrm{C} /$ min on a TGA 2050 apparatus.

Solid-phase ${ }^{13} \mathrm{C}$ and ${ }^{1} \mathrm{H}$ NMR spectroscopies were performed on a BioSpin $\mathrm{GmbH}$, Bruker spectrometer. $\mathrm{H}_{3} \mathrm{PO}_{4}$ $(85 \%)$ was used as an external reference.

Table 1 Complexation tests

\begin{tabular}{lllll}
\hline Cations & Reagents & Initial color & Products & Final color \\
\hline $\mathrm{Cu}^{2+}$ & $\mathrm{CH}_{3} \mathrm{COOH}(5 \mathrm{ml}, 6 \mathrm{M})+\mathrm{K}_{4} \mathrm{Fe}(\mathrm{CN})_{6}(1 \mathrm{ml}, 0.5 \mathrm{M})$ & Blue & $\mathrm{Cu} \mathrm{Fe}_{2}(\mathrm{CN})_{6}$ & $\mathrm{Red} \mathrm{brown}$ \\
$\mathrm{Mn}^{2+}$ & $\mathrm{H}_{2} \mathrm{O}_{2}(3 \mathrm{ml}, 30 \%)+\mathrm{HNO}_{3}(4 \mathrm{ml}, 0.5 \mathrm{M})+\mathrm{KIO}_{4}$ & Purple & $\mathrm{MnO}_{2}, n \mathrm{H}_{2} \mathrm{O}$ & $\mathrm{Black}$ \\
$\mathrm{Zn}^{2+}$ & $\mathrm{HCl}(1 \mathrm{ml}, 3 \mathrm{M})+\mathrm{K}_{4} \mathrm{Fe}(\mathrm{CN})_{6}(3 \mathrm{ml}, 1 \mathrm{M})$ & White & $/$ & $\mathrm{Transparent}$ \\
$\mathrm{Co}^{2+}$ & $\mathrm{NH}_{4} \mathrm{SCN}(0.5 \mathrm{~g})+$ amyl alcohol $(3 \mathrm{ml})+$ acetic acid (solvent $)$ & Blue & {$\left[\mathrm{Co}(\mathrm{SCN})_{4}\right]^{2-}$} & $\mathrm{Blue}$ \\
$\mathrm{Ni}^{2+}$ & Dimethylglyoxime $(3 \mathrm{ml})$ & Red & $/$ & Red brown \\
\hline
\end{tabular}




\section{Catalytic reaction}

Cyclohexanone oxidation was performed according to the literature [32]. A mixture constituting the substrate (-one) and catalyst was introduced into a flask under stirring (1000 rpm) and heated at $90{ }^{\circ} \mathrm{C}$ under a reflux condenser. After few minutes, the reaction mixture yellow in color turns blue, the characteristic color of reduced POM $\left(\mathrm{Mo}^{\mathrm{V}}\right)$. Then, hydrogen peroxide was added to restore the initial color, the characteristic color of oxidized POM $\left(\mathrm{Mo}^{\mathrm{VI}}\right)$. This operation is repeated after each catalyst reduction. The end of the reaction is reached when the POM is no longer reduced, thus indicating the total substrate consumption. After $20 \mathrm{~h}$ of reaction time, the mixture was cooled to $4{ }^{\circ} \mathrm{C}$ and then the white crystals of adipic acid were recovered after almost two nights and weighed (w (AA) $)_{\text {exp }}$ ). The AA purity was verified by melting point $\left(152^{\circ} \mathrm{C}\right)$ and FT-IR and NMR spectroscopies $\left({ }^{13} \mathrm{C}\right.$ and $\left.{ }^{1} \mathrm{H}\right)$. Hydrogen peroxide concentration was verified by potassium permanganate dosage before performing the catalytic test. The adipic acid yield was calculated by following formula:

AA yield $(\%)=100 \times w(A A)_{\exp } / w(A A)_{\text {the }}$

\section{Results and discussion}

\section{Characterization results}

FT-IR spectra of $\mathrm{HMPMo}_{12} \mathrm{O}_{40}$ (Fig. 1) showed the characteristic vibration bands of the Keggin structure in the spectral range of $1200-400 \mathrm{~cm}^{-1}$ [36]. The vibration band corresponding to phosphorus-oxygen, $v_{\text {as }} \mathrm{P}-\mathrm{O}_{\mathrm{a}}$, was observed at $1062 \mathrm{~cm}^{-1}$ and those assigned to metal-oxygen, $v_{\text {as }}$ Mo- $-\mathrm{O}_{\mathrm{d}}, v_{\text {as }}$ Mo- $-\mathrm{O}_{\mathrm{b}}-$ Mo and $v_{\text {as }}$ Mo- $-\mathrm{O}_{\mathrm{c}}-$ Mo at 960,860 and $780 \mathrm{~cm}^{-1}$, respectively. The proton partial substitution of $\mathrm{H}_{3} \mathrm{PMo}_{12} \mathrm{O}_{40}$ by transition metal $(\mathrm{Co}, \mathrm{Ni}, \mathrm{Mn}, \mathrm{Cu}$ or $\mathrm{Zn})$ does not reveal a significant variation in frequency values of different IR vibration bands, confirming thus that the introduction of a metal atom in cationic position does not disturb the Keggin anion symmetry as already reported in other studies $[4,26]$.

The UV-visible spectra of different solids (Fig. 2) show a large charge transfer band oxygen-molybdenum(VI) in 200-480 nm range, consisting of two components located at $200-300$ and $300-450 \mathrm{~nm}[11,27]$. The latter are associated with the different types of oxygen atoms of the Keggin anion, inter-anion charge transfer transitions and counter-ion nature. In the case of $\mathrm{HZnPMo}_{12} \mathrm{O}_{40}$, the second component is slightly shifted to higher wavelength. This difference can be attributed to a non-transition metal character and/or saturated $d$ atomic orbital $\left(d^{10}\right)$ of $\mathrm{Zn}$.

The TG curves of the samples (not represented here) show different mass losses. The first loss was observed in the temperature range $50-180{ }^{\circ} \mathrm{C}$, corresponding to the departure of 8-13 hydration water molecules. The second one, observed in the range $180-380{ }^{\circ} \mathrm{C}$, was attributed to the departure of half constitution water molecule $\left(1 / 2 \mathrm{H}_{2} \mathrm{O}\right)$ that results from the combination of proton with an oxygen atom of the Keggin anion. Above $400{ }^{\circ} \mathrm{C}$, the POM decomposition to $\mathrm{P}_{2} \mathrm{O}_{5}, \mathrm{MoO}_{3}$ and $\mathrm{MO}$ occurred. The TG analysis results are reported in the Table 2. A good correlation between the experimental and theoretical formulas was observed, confirming also the reliability of the cationic exchange synthesis method.

\section{Catalytic performances of $\mathrm{HMPMO}_{12} \mathrm{O}_{40}$ for adipic acid synthesis}

The reaction products are adipic, glutaric and succinic acids. In this work, only adipic acid (AA) was considered. It was isolated by crystallization at $4{ }^{\circ} \mathrm{C}$ and characterized by FT-IR and NMR spectroscopies $\left({ }^{13} \mathrm{C}\right.$ and $\left.{ }^{1} \mathrm{H}\right)$. The IR spectrum of adipic acid (Fig. 3) shows an intense vibration band located at $1700 \mathrm{~cm}^{-1}$ and another more broad at $3000 \mathrm{~cm}^{-1}$,
Fig. 1 FT-IR spectra of $\mathrm{HMPMo}_{12} \mathrm{O}_{40}$

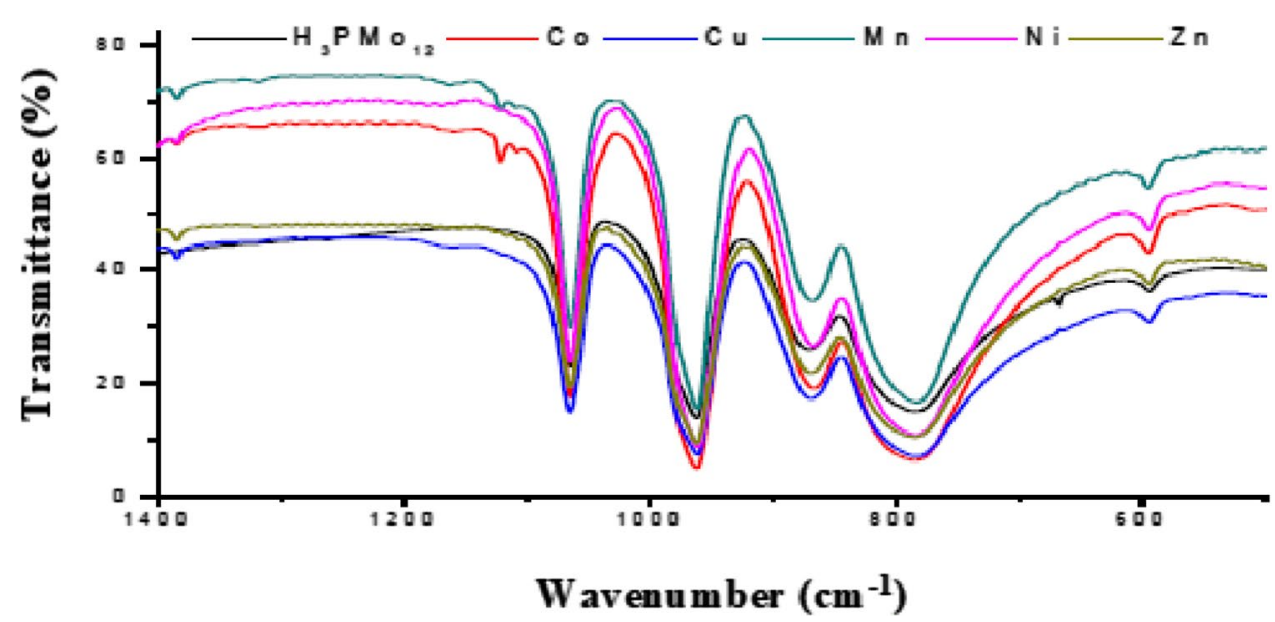

Wavenumber $\left(\mathrm{cm}^{-1}\right)$ 
Fig. 2 UV-visible spectra of $\mathrm{HMPMo}_{12} \mathrm{O}_{40}$

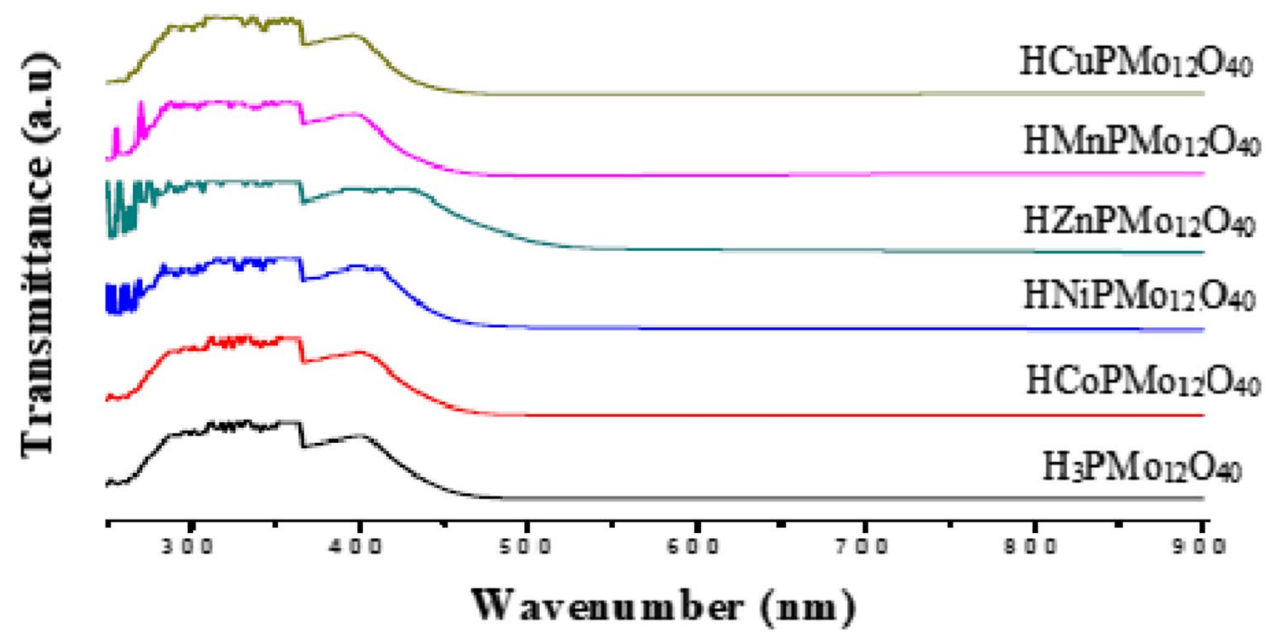

Table 2 Thermal analysis results of $\mathrm{HMPMo}_{12} \mathrm{O}_{40}$ salts

\begin{tabular}{ll}
\hline Theoretical formula & Experimental formula \\
\hline $\mathrm{H}_{1.00} \mathrm{Co}_{1.00} \mathrm{PMo}_{12} \mathrm{O}_{40}$ & $\mathrm{H}_{0.87} \mathrm{Co}_{1.07} \mathrm{PMo}_{12} \mathrm{O}_{40}$ \\
$\mathrm{H}_{1.00} \mathrm{Zn}_{1.00} \mathrm{PMo}_{12} \mathrm{O}_{40}$ & $\mathrm{H}_{1.04} \mathrm{Zn}_{0.98} \mathrm{PMo}_{12} \mathrm{O}_{40}$ \\
$\mathrm{H}_{1.00} \mathrm{Mn}_{1.00} \mathrm{PMo}_{12} \mathrm{O}_{40}$ & $\mathrm{H}_{0.94} \mathrm{Mn}_{1.03} \mathrm{PMo}_{12} \mathrm{O}_{40}$ \\
$\mathrm{H}_{1.00} \mathrm{Cu}_{1.00} \mathrm{PMo}_{12} \mathrm{O}_{40}$ & $\mathrm{H}_{0.97} \mathrm{Co}_{1.01} \mathrm{PMo}_{12} \mathrm{O}_{40}$ \\
$\mathrm{H}_{1.00} \mathrm{Ni}_{1.00} \mathrm{PMo}_{12} \mathrm{O}_{40}$ & $\mathrm{H}_{0.94} \mathrm{Ni}_{1.03} \mathrm{PMo}_{12} \mathrm{O}_{40}$ \\
\hline
\end{tabular}

characteristic of the $\mathrm{C}=\mathrm{O}$ and $\mathrm{O}-\mathrm{H}$ bonds of the carboxylic acid, respectively.

The ${ }^{1} \mathrm{H}$ NMR spectrum shows two signals at 1.65 and $2.33 \mathrm{ppm}$ corresponding to methyl groups $-\mathrm{CH}_{2}-$ and a peak associated with the proton of the $-\mathrm{COOH}$ group at 10.48 ppm (Fig. 4). The ${ }^{13} \mathrm{C}$ NMR spectrum shows two peaks at 25.11 and $38.83 \mathrm{ppm}$, assigned to carbon atoms of methyl groups $-\mathrm{CH}_{2}-$ and a signal at $174.39 \mathrm{ppm}$ characteristic of the carbon atom of the carboxylic group (Fig. 5). The peaks observed at $2.06 \mathrm{ppm}$ in ${ }^{1} \mathrm{H}$ NMR (Fig. 4) and at around 29.84 and $206.23 \mathrm{ppm}$ in ${ }^{13} \mathrm{C}$ NMR (Fig. 5) are associated with the acetone solvent.

\section{Adipic acid synthesis from cyclohexanone oxidation}

In the preliminary tests carried out with $\mathrm{H}_{3} \mathrm{PMo}_{12} \mathrm{O}_{40}$ for the cyclohexanone oxidation at $90{ }^{\circ} \mathrm{C}$ during $20 \mathrm{~h}$, no crystal, corresponding to the adipic acid formation, was observed after cold conditions $\left(4^{\circ} \mathrm{C}\right)$ overnight, when the reaction mixture constituted of: (1) cyclohexanone and catalyst, (2) substrate, catalyst and hydrogen peroxide and (3) substrate and hydrogen peroxide. In the first case (1), the POM oxidizes the substrate that is visualized by the change in color from blue to yellow. In the second case (2), the reaction mixture turns to blue, attesting to the reduction of POM. The latter can oxidize both cyclohexanone and hydrogen peroxide $\left(\mathrm{H}_{2} \mathrm{O}_{2}\right.$ being amphoteric). POM has a higher oxidizing power than $\mathrm{H}_{2} \mathrm{O}_{2}$. In case (3), the substrate has probably reacted with hydrogen peroxide. From these observations, it is necessary to apply the procedure mentioned in the experimental part.

The catalytic performances of $\mathrm{HMPMo}_{12} \mathrm{O}_{40}$ are summarized in Table 3. The proton partial substitution by cobalt or copper seems to have no effect on the catalytic behavior of $\mathrm{H}_{3} \mathrm{PMo}_{12} \mathrm{O}_{40}$ (25 and 29 , respectively,
Fig. 3 FT-IR spectrum of adipic acid

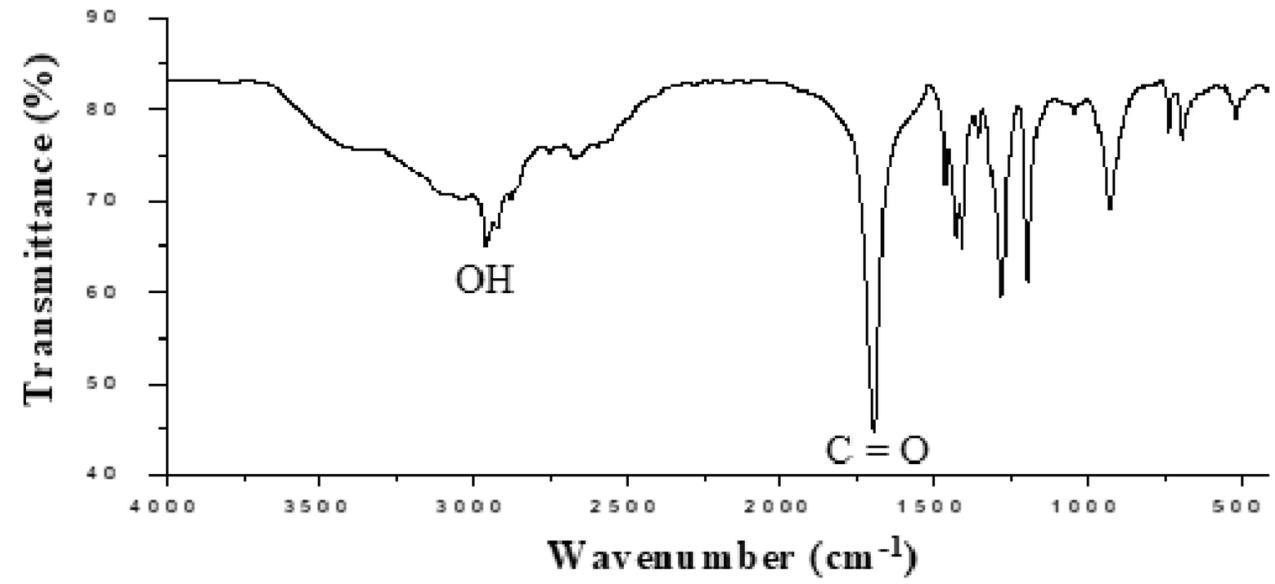


Fig. $4{ }^{1} \mathrm{HNMR}$ spectra of adipic acid

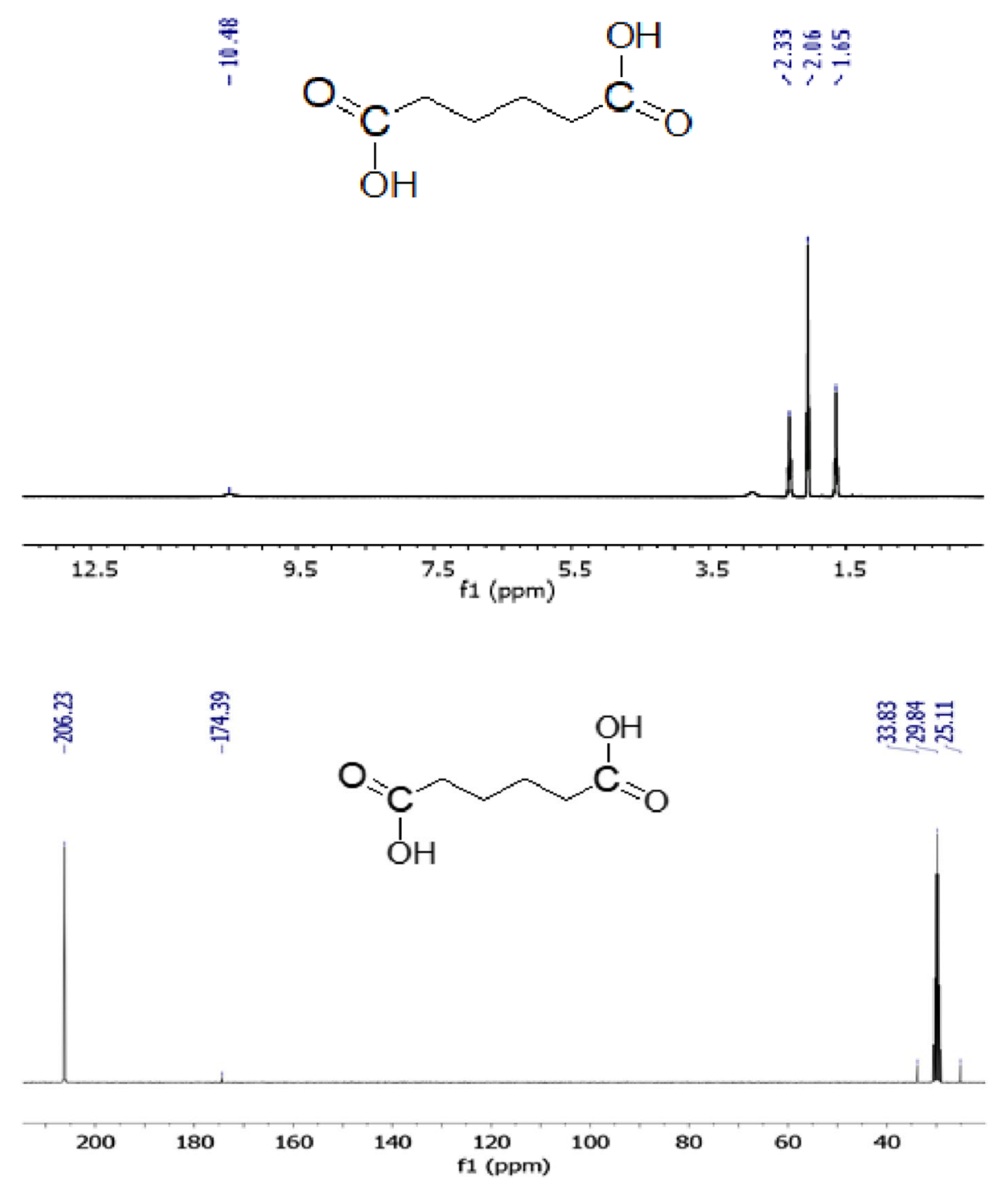

Fig. $5{ }^{13}$ CNMR spectra of adipic acid
Table 3 AA yields as a function of POM composition

\begin{tabular}{ll}
\hline Catalyst & AA yield (\%) \\
\hline $\mathrm{H}_{3} \mathrm{PMo}_{12} \mathrm{O}_{40}$ & 28 \\
$\mathrm{HCoPMo}_{12} \mathrm{O}_{40}$ & 25 \\
$\mathrm{HNiPMo}_{12} \mathrm{O}_{40}$ & 2 \\
$\mathrm{HMnPMo}_{12} \mathrm{O}_{40}$ & 16 \\
$\mathrm{HCuPMo}_{12} \mathrm{O}_{40}$ & 29 \\
$\mathrm{HZnPMo}_{12} \mathrm{O}_{40}$ & 41
\end{tabular}

Conditions $T_{\text {react }}=90{ }^{\circ} \mathrm{C}$, agitation rate: $1000 \mathrm{rpm}$, reaction time $=20 \mathrm{~h}, m_{\text {catalyst }}=0.03 \mathrm{~g}$, $n_{\text {-one }}=30 \mathrm{mmol}, \mathrm{H}_{2} \mathrm{O}_{2}$ addition mode: $0.5-0.1 \mathrm{ml}$ against $28 \%$ of AA yield). The introduction of manganese or nickel strongly decreases the AA yield from 28 to 16 and $2 \%$, respectively, whereas the presence of zinc leads to a strong AA yield increase (41 against 2-29\%). The difference in catalytic behavior can be attributed to several parameters: (1) its non-transition metal character, (2) presence of a saturated d atomic orbital $\left(d^{10}\right), \mathrm{Zn}$ (II) behaves like a Lewis acid that would promote substrate activation, (3) a non-reducible character that would more easily give peroxo entities $\left(\mathrm{ZnO}_{2}\right)$. These properties seem to create a moderate oxidative power that can favor AA formation to the detriment of those of other oxygenated products. This observation has already been signaled in the case of the vanadium substituted molybdenum in the Dawson type POMs [30].

Figure 6 presents the AA yield variation, with an error bar of $3 \%$, as a function of catalyst/-one molar ratio. The -one oxidation was carried out in the presence of $\mathrm{HZnPMo}_{12} \mathrm{O}_{40}$. The AA yield decreases from 41 to $7 \%$ when catalyst/-one molar ratio increases from $0.47 \times 10^{-3}$ to $1.41 \times 10^{-3}$. The maximum AA yield (53\%) was reached with a catalyst/-one molar ratio of $1.89 \times 10^{-3}$ (catalyst: 
Fig. 6 AA yields as a function of catalyst/-one molar ratio, (catalyst: $\mathrm{HZnPMo}_{12} \mathrm{O}_{40}, T_{\text {react }}=$ $90{ }^{\circ} \mathrm{C}$, agitation rate: $1000 \mathrm{rpm}$, reaction time $=20 \mathrm{~h}, \mathrm{H}_{2} \mathrm{O}_{2}$ addition mode: $0.5-0.1 \mathrm{ml}$ )

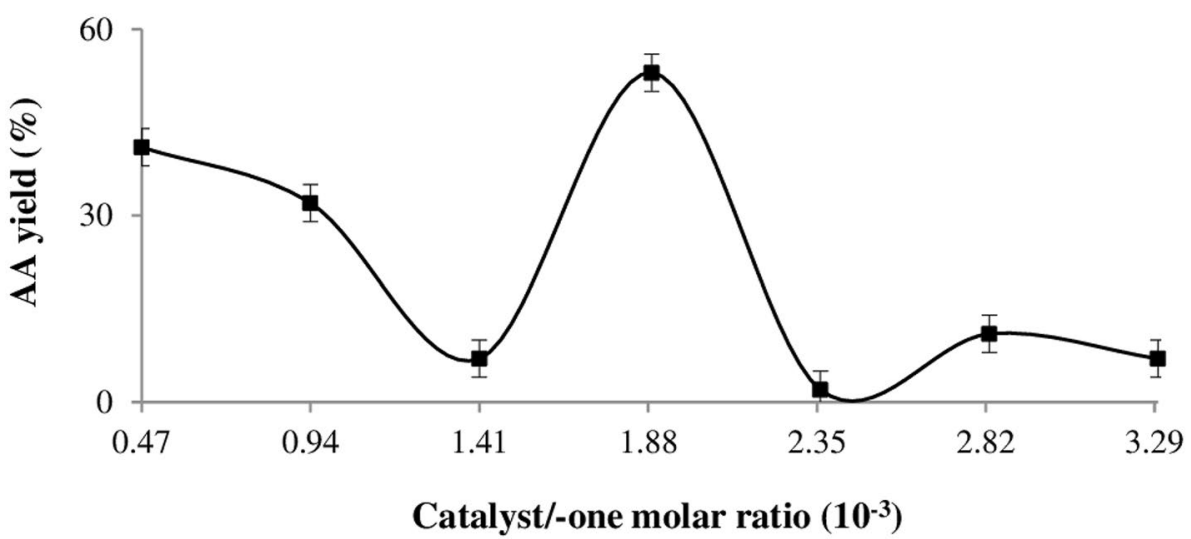

$0.12 \mathrm{~g}$, cyclohexanone: $30 \mathrm{mmol}$ ). At higher ratios, AA yield drop from 53 to $2 \%$ was observed.

\section{Adipic acid synthesis from cyclohexanone/ cyclohexanol oxidation}

The AA synthesis was also performed via -one/-ol mixture oxidation in the presence of $\mathrm{HZnPMo}_{12} \mathrm{O}_{40}$, with a catalyst/-one molar ratio of $1.89 \times 10^{-3}$. Different -one/-ol ratios were examined $(100 / 0,75 / 25,50 / 50,25 / 75,100 / 0)$. The obtained results (Fig. 7) showed that ketone oxidation alone led to 53\% of AA yield and that of alcohol alone to $9 \%$, whereas similar AA yields (4-5\%) were obtained with -one/-ol ratios of 75/25 and 25/75. With an equimolar mixture (50/50\%), AA formation was not observed, contrarily to the industrial process. The negative effect of alcohol presence in the reaction mixture has already been mentioned $[4,8,20,26,28,39]$. It was attributed to the formation of hydrogen bonds between the $\mathrm{C}=\mathrm{O}$ group of the ketone and the hydrogen of the $\mathrm{C}-\mathrm{OH}$ group of cyclohexanol, which makes the -one oxidation of the mixture difficult.

\section{Comparative study}

Table 4 shows the adipic acid yields obtained by oxidation of cyclohexanone over various catalysts reported in literature. The use of various organic and inorganic solvents and $\mathrm{Mn} /$ Co-based materials as catalyst leads to AA yields slightly higher compared to those obtained with Dawson or Keggin POMs as catalysts, in free solvent (75-91\% against 57-75\%). It is noted that the AA yields (57-75\%) are higher than those obtained with vanadium based POMs, in the presence of $\mathrm{CH}_{3} \mathrm{COOH}, \mathrm{CH}_{3} \mathrm{CN}, \mathrm{CH}_{3} \mathrm{OH}$ as solvent (50-54\%). These latter's are similar to that obtained with $\mathrm{HZnPMo}_{12} \mathrm{O}_{40}$ (53\%) used in this study. In conclusion, the comparison between these different processes shows well that the use of POMs in the absence of the solvent leads to a process that is much cleaner and with appreciable AA yields.

\section{Reaction pathway}

The catalytic process of cyclohexanone oxidation by hydrogen peroxide in the presence of POM is composed of three steps. The first step corresponds to the substrate oxidation by
Fig. 7 AA yields as a function of -one/-ol mixture composition (catalyst: $\mathrm{HZnPMo}{ }_{12} \mathrm{O}_{40}$, $T_{\text {react }}=90^{\circ} \mathrm{C}$, agitation rate: $1000 \mathrm{rpm}$, reaction time $=20 \mathrm{~h}, m_{\text {catalyst }}=0.12 \mathrm{~g}$, $n_{\text {-one }}=30 \mathrm{mmol}, \mathrm{H}_{2} \mathrm{O}_{2}$ addition mode: $0.5-0.1 \mathrm{ml}$ )

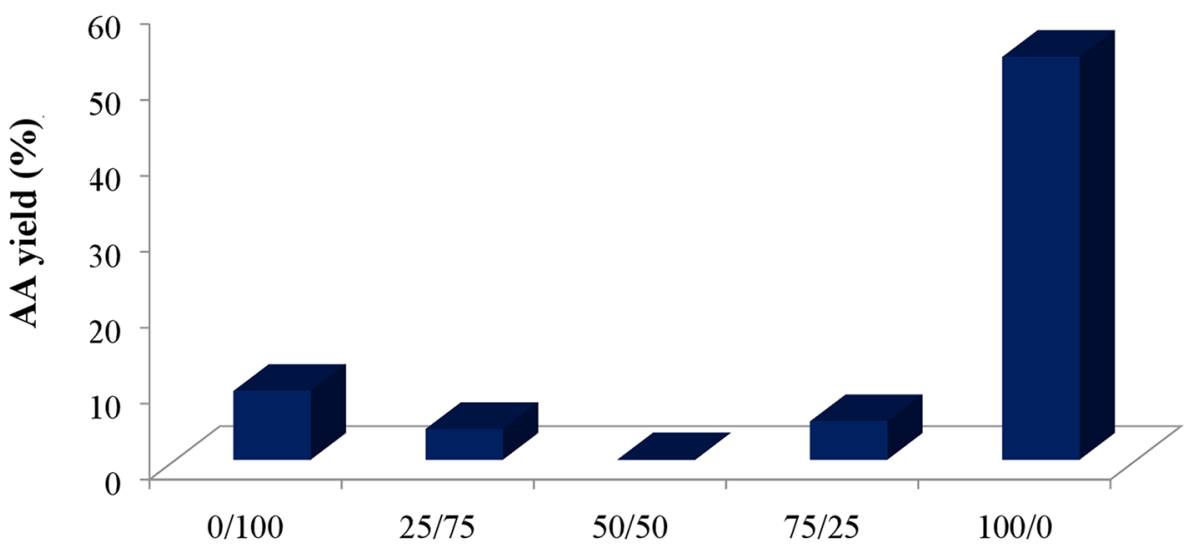

-one/-ol mixture composition 
Table 4 Comparison between several processes of adipic acid synthesis from cyclohexanone oxidation

\begin{tabular}{llrll}
\hline Catalyst & Solvent & $\mathrm{T}\left({ }^{\circ} \mathrm{C}\right)$ & AA yield $(\%)$ & Refs. \\
\hline $\mathrm{Mn}(\mathrm{OAc})_{2}$ & $\mathrm{CH}_{3} \mathrm{COOH} / \mathrm{CF}_{3} \mathrm{COOH}$ & 65 & 75 & {$[10]$} \\
$\mathrm{Mn}\left(\mathrm{NO}_{3}\right)_{2} / \mathrm{Co}\left(\mathrm{NO}_{3}\right)_{2}$ & $\mathrm{CH}_{3} \mathrm{COOH}+\mathrm{HNO}_{3}$ & 40 & 91 & {$[15]$} \\
$\mathrm{Co} / \mathrm{Mn} \mathrm{cluster}^{\mathrm{CH}_{3} \mathrm{COOH} / \mathrm{H}_{2} \mathrm{O}}$ & 100 & 85 & {$[6]$} \\
$\mathrm{H}_{7} \mathrm{PMo}_{8} \mathrm{~V}_{4} \mathrm{O}_{40}$ & $\mathrm{CH}_{3} \mathrm{COOH} / \mathrm{H}_{2} \mathrm{O}$ & 70 & 50 & {$[3]$} \\
$\mathrm{H}_{5} \mathrm{PMo}_{10} \mathrm{~V}_{2} \mathrm{O}_{40}$ & $\mathrm{CH}_{3} \mathrm{CN} / \mathrm{CH}_{3} \mathrm{OH}$ & 60 & 54 & {$[9]$} \\
$\mathrm{H}_{1} \mathrm{Mn}_{0.25} \mathrm{Co}_{0.75} \mathrm{PMo}_{12} \mathrm{O}_{40} 75[28]$ & Free & 90 & 75 & {$[29]$ (in press) } \\
$\mathrm{K}_{6} \mathrm{P}_{2} \mathrm{Mo}_{6} \mathrm{~W}_{12} \mathrm{O}_{62}$ & Free & 90 & 58 & {$[30]$} \\
$\left(\mathrm{NH}_{4}\right)_{0,5} \mathrm{Sn}_{1.25} \mathrm{PMo}_{12} \mathrm{O}_{40}$ & Free & 90 & 57 & {$[31]$} \\
$\mathrm{HZnPMo}_{12} \mathrm{O}_{40}$ & Free & 90 & 53 & This work \\
\hline
\end{tabular}

the POM. The latter changes color from yellow, the characteristic color of POM at the oxidized state (noted POMox), to blue, the characteristic color of POM at the reduced state (noted POMred). It was reported that the POMox, corresponding to $\left[\mathrm{PMo}_{12} \mathrm{O}_{40}\right]^{3-}$, Keggin anion (noted $\alpha(0)$ ), undergoes successive reductions from $\alpha$ (0) to $\alpha$ (II) and $\beta$ (II) $\left[\mathrm{PMo}_{12} \mathrm{O}_{40}\right]^{5-}$ and to $\alpha(\mathrm{IV})$ and $\beta(\mathrm{IV})\left[\mathrm{PMo}_{12} \mathrm{O}_{40}\right]^{7-}$, in the presence of the reducing agent [2]. In addition, a Mars and Van Krevelen mechanism can be assumed, in which POMox oxygen atoms participate in the oxidation process by giving lacunary POMs (noted POM lac) as $\left[\mathrm{PMo}_{11} \mathrm{O}_{39}\right]^{7-}$ and $\left[\mathrm{PMo}_{9} \mathrm{O}_{34}\right]^{9-}$ [25]. In these latter species, there is a departure of both molybdenum and oxygen atoms (Eq. 1). On the other hand, during this first step, a keto-enol tautomeric equilibrium catalyzed by the Brønsted acidity of the POM $\left(\mathrm{HMPMo}{ }_{12} \mathrm{O}_{40}\right)$ is attained, a necessary step for substrate activation (Eq. 2).

This step can be explained by the following reactions shown in the equations (Eqs. 1 and 2) that take place simultaneously:

Substrate + POMox $\rightarrow$ products + POMred + POMlac.

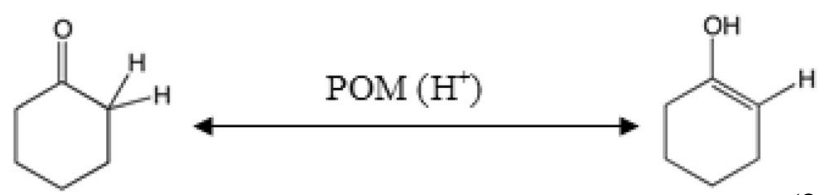

In the second step, the addition of hydrogen peroxide led to a POM color change from blue to yellow that is attributed to the POMred oxidation. It was reported that in the presence of hydrogen peroxide, peroxo species such as $\left\{\mathrm{PO}_{4}\left[\mathrm{MoO}\left(\mathrm{O}_{2}\right)_{2}\right]_{4}\right\}^{3-},\left\{\mathrm{PMo}_{3} \mathrm{O}_{\mathrm{m}}\right\}^{n-}$ and $\left\{\mathrm{PO}_{4}\left[\mathrm{MoO}\left(\mathrm{O}_{2}\right)_{2}\right]_{2}\right\}^{2-}$ (noted peroxo-POM) are formed, as evidenced by multinuclear NMR spectroscopy $[2,21]$. This step can be explained by the following equation:

POMred $+\mathrm{H}_{2} \mathrm{O}_{2} \rightarrow$ peroxo-species
During the $20 \mathrm{~h}$ of reaction, the peroxo-POM species will react with some products from the Eq. (1) to form final products including adipic acid according with Eq. (4). In this last step, we can also assume another similar mechanism to that of Mars and Van Krevelen, where the oxygen atoms of the peroxo-POM would intervene in the intermediate products' oxidation:

Peroxo $-\mathrm{POM}_{\mathrm{ox}}+$ intermediate species
$\quad \rightarrow$ reaction products + POMox

\section{Conclusion}

The oxidation of cyclohexanone and that of cyclohexanol/ cyclohexanone mixture was carried out in the homogenous phase at $90{ }^{\circ} \mathrm{C}$ using $\mathrm{H}_{2} \mathrm{O}_{2}(30 \%)$ in the presence of a series of Keggin-type POMs of formula $\mathrm{HMPMo}_{12} \mathrm{O}_{40}$ (M:Co, $\mathrm{Ni}, \mathrm{Mn}, \mathrm{Cu}$ or $\mathrm{Zn}$ ).

The formulation, $\mathrm{HMPMo}_{12} \mathrm{O}_{40}$, was evidenced by TG analysis for proton amount and complexation characteristic test of each metal in the cationic position. FT-IR and $\mathrm{UV}-\mathrm{Vis}$ spectroscopies have evidenced the Keggin anion structure.

The catalytic results showed that $\mathrm{HZnPMo}_{12} \mathrm{O}_{40}$ exhibits the highest adipic acid yield (53\%), evidencing the efficiency of the presence of a metal compared to that of a transition metal as a counter-ion of the $\left[\mathrm{PMo}_{12} \mathrm{O}_{40}\right]^{3-}$ system.

A reaction pathway was proposed showing different steps of the oxidation process.

The use of both hydrogen peroxide, green oxidant and $\mathrm{HMPMo}_{12} \mathrm{O}_{40}$, non-polluting catalyst can be an attractive route for developing a clean adipic acid industrial process compared to the $\mathrm{HNO}_{3}$ method.

Open Access This article is distributed under the terms of the Creative Commons Attribution 4.0 International License (http://creativeco mmons.org/licenses/by/4.0/), which permits unrestricted use, distribution, and reproduction in any medium, provided you give appropriate credit to the original author(s) and the source, provide a link to the Creative Commons license, and indicate if changes were made.

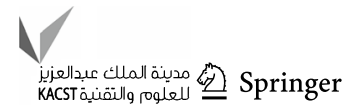




\section{References}

1. Alcaniz-Monge J, Trautwein G, Garcia-Garcia A (2014) Influence of peroxometallic intermediaries present on polyoxometalates nanoparticles surface on the adipic acid synthesis. J Mol Catal A Chem 394:211-216. https://doi.org/10.1016/j.molca ta.2014.07.023

2. Amitouche D, Haouas M, Mazari T, Mouanni S, Canioni R, Rabia C, Cadot E, Marchal-Roch C (2018) The primary stages of polyoxomolybdate catalyzed cyclohexanone oxidation by hydrogen peroxide as investigated by in situ NMR. Substrate activation and evolution of the working catalyst. Appl Catal A Gen 561:104-116. https://doi.org/10.1016/j.apcata.2018.05.017

3. Atlamsani A, Brégeault JM, Ziyad M (1993) Oxidation of 2-methylcyclohexanone and cyclohexanone by dioxygen catalyzed by vanadium-containing heteropolyanions. J Org Chem 58:5663-5665. https://doi.org/10.1021/jo00073a026

4. Benadji S, Mazari T, Dermeche L, Salhi N, Cadot E, Rabia C (2013) Clean alternative for adipic acid synthesis via liquidphase oxidation of cyclohexanone and cyclohexanol over $\mathrm{H}_{3-2 x} \mathrm{Co}_{x} \mathrm{PMo}_{12} \mathrm{O}_{40}$ catalysts with hydrogen peroxide. Catal Lett 143:749-755. https://doi.org/10.1007/s10562-013-1025-3

5. Blach P, Böstrom Z, Franceschi-Messant S, Lattes A, Perez E, Rico-Lattes I (2010) Recyclable process for sustainable adipic acid production in microemulsions. Tetrahedron 66:7124-7128. https://doi.org/10.1016/j.tet.2010.06.093

6. Brégeault JM, Bassam EA, Martin J (1991) US Patent 4: 983, 767

7. Cavallaro A, Bart JCJ, Cavallaro S (1991) Industrial production and use of adipic acid. Catal Today 9:237-254. https://doi. org/10.1016/0920-5861(91)80049-F

8. Cavani F, Ferronia L, Frattini A, Lucarelli C, Mazzinia A, Raabova K, Alini S, Accorinti P, Babini P (2011) Evidence for the presence of alternative mechanisms in the oxidation of cyclohexanone to adipic acid with oxygen, catalysed by Keggin polyoxometalates. Appl Catal A Gen 391:118-124. https://doi. org/10.1016/j.apcata.2010.04.032

9. Chavan SA, Srinivas D, Ratnasamy P (2002) Oxidation of cyclohexane, cyclohexanone, and cyclohexanol to adipic acid by a non- $\mathrm{HNO}_{3}$ route over $\mathrm{Co} / \mathrm{Mn}$ cluster complexes. J Catal 212:3945. https://doi.org/10.1006/jcat.2002.3756

10. Constantini M, Krumenacker L (1983) FR Patent 2: 541, 993

11. Dermeche L, Thouvenot R, Hocine S, Rabia C (2009) Preparation and characterization of mixed ammonium salts of Keggin phosphomolybdate. Inorg Chem Acta 362:3896-3900. https://doi. org/10.1016/j.ica.2009.04.049

12. Ding Y, Gao Q, Li G, Zhang H, Wang J, Yan L, Suo J (2004) Selective epoxidation of cyclohexene to cyclohexene oxide catalyzed by Keggin-type heteropoly compounds using anhydrous urea-hydrogen peroxide as oxidizing reagent and acetonitrile as the solvent. J Mol Catal A Chem 218:161-170. https://doi. org/10.1016/j.molcata.2004.04.019

13. Ding Y, Ma B, Gao Q, Li G, Yan L, Suo J (2005) A spectroscopic study on the 12-heteropolyacids of molybdenum and tungsten $\left(\mathrm{H}_{3} \mathrm{PMo}_{12-n} \mathrm{~W}_{n} \mathrm{O}_{40}\right)$ combined with cetylpyridinium bromide in the epoxidation of cyclopentene. J Mol Catal A Chem 230:121-128. https://doi.org/10.1016/j.molcata.2004.12.017

14. Duncan DC, Chambers RC, Hecht E, Hill CL (1995) Mechanism and dynamics in the $\mathrm{H}_{3}\left[\mathrm{PW}_{12} \mathrm{O}_{40}\right]$ catalyzed selective epoxidation of terminal olefins by $\mathrm{H}_{2} \mathrm{O}_{2}$. Formation, reactivity, and stability of $\left\{\mathrm{PO}_{4}\left[\mathrm{WO}\left(\mathrm{O}_{2}\right)_{2}\right]_{4}\right\}^{3-}$. J Am Chem Soc 117:681-691. https://doi. org/10.1021/ja00107a012

15. Fumagalli C, Minisci F, Pirola R (2001) WO Patent 01/87, 815

16. Frenzel R, Sathicq ÁG, Blanco MN, Romanelli GP, Pizzio LR (2015) Carbon-supported metal-modified lacunary tungstosilicic polyoxometallates used as catalysts in the selective oxidation of sulphides. Mol Catal A Chem 403:27-36. https:// doi.org/10.1016/j.molcata.2015.02.021

17. Ghosh S, Acharyya SS, Adak S, Konathala LS (2014) Selective oxidation of cyclohexene to adipic acid over silver supported tungsten oxide nanostructured catalysts. Green Chem 16:2826-2834. https://doi.org/10.1039/c4gc00130c

18. Ishii Y, Yamawaki K, Ura T, Yamada H, Yoshida T, Ogawa M (1988) Hydrogen peroxide oxidation catalyzed by heteropoly acids combined with cetylpyridinium chloride: epoxidation of olefins and allylic alcohols, ketonization of alcohols and diols, and oxidative cleavage of 1,2-diols and olefins. Org Chem 53:3581-3593. https://doi.org/10.1021/jo00250a032

19. Iwahama T, Syojyo K, Sakaguchi S, Ishii Y (1998) Direct conversion of cyclohexane into adipic acid with molecular oxygen catalyzed by $n$-hydroxyphthalimide combined with $\mathrm{Mn}(\mathrm{acac})_{2}$ and $\mathrm{Co}(\mathrm{OAc})_{2}$. Org Process Res Dev 2:255-260. https://doi. org/10.1021/op980016y

20. Katsoulis DE (1998) A survey of applications of polyoxometalates. Chem Rev 98:359. https://doi.org/10.1021/cr960398a

21. Kuznetsova LI, Kuznetsova NI, Maksimovskaya RI, Koshcheeva OS, Utkin VA (2013) Catalytic properties of heteropoly compounds in 1,3-butadiene oxidation with hydrogen peroxide. Kinet Catal 54:420-430. https://doi.org/10.1134/S002315841 3040071

22. Leont'ev AV, Fomicheva OA, Proskurnina MV, Zefirov NS (2001) Modern chemistry of nitrous oxide. Russ Chem Rev 70:91-104. https://doi.org/10.1070/RC2001v070n02ABEH000 631

23. Li H, She Y, Fu H, Cao M, Wang J, Wang T (2015) Synergistic effect of co-reactant promotes one-step oxidation of cyclohexane into adipic acid catalyzed by manganese porphyrins. Can J Chem 93:696-701. https://doi.org/10.1139/cjc-2014-0515

24. Luo J, Huang Y, Ding B, Wang P, Geng X, Zhang J, Wei Y (2018) Single-atom $\mathrm{Mn}$ active site in a triol-stabilized $\beta$-Anderson manganohexamolybdate for enhanced catalytic activity towards adipic acid production. Catalysts 8:121. https://doi.org/10.3390/catal 8030121

25. Maksimovskaya RI (2013) Molybdophosphate heteropoly blues: electron-transfer reactions in aqueous solutions as studied by NMR. Polyhedron 65:54-59. https://doi.org/10.1016/j. poly.2013.08.014

26. Mazari T, Benadji S, Tahar A, Dermeche L, Rabia C (2013) Simple and green liquid-phase synthesis of adipic acid using Keggintype phosphomolybdates catalysts. J Mat Sci Eng B 3:146-152. https://doi.org/10.1016/j.molcata.2014.07.023

27. Mazari T, Marchal-Roch C, Hocine S, Salhi N, Rabia C (2009) Oxidation of propane over substituted Keggin phosphomolybdate salts. J Nat Gas Chem 18:319-324. https://doi.org/10.1016/S1003 $-9953(08) 60111-5$

28. Mouanni S, Mazari T, Benadji S, Dermeche L, Marchal-Roch C, Rabia C (2018) Simple and green adipic acid synthesis from cyclohexanone and/or cyclohexanol oxidation with efficient $\left(\mathrm{NH}_{4}\right)_{x} \mathrm{H}_{y} \mathrm{M}_{z} \mathrm{PMo}_{12} \mathrm{O}_{40}(\mathrm{M}: \mathrm{Fe} \mathrm{Co}, \mathrm{Ni})$ catalysts. BREC 13:386-391

29. Mouanni S, Mazari T, Amitouche D, Benadji S, Dermeche L, Roch-Marchal C, Rabia C (2019) Preparation and characterization of $\mathrm{H}_{3-2(x+y)} \mathrm{Mn}_{x} \mathrm{Co}_{y} \mathrm{PMo}_{12} \mathrm{O}_{40}$ heteropolysalts. Application to adipic acid green synthesis from cyclohexanone oxidation with hydrogen peroxide. C R Chim. https://doi.org/10.1016/j. crci.2019.01.003

30. Moudjahed M, Dermeche L, Benadji S, Mazari T, Rabia C (2016) Dawson-type polyoxometalates as green catalysts for adipic acid synthesis. Mol Catal A Chem 414:72-77. https://doi. org/10.1016/j.molcata.2015.12.014

31. Mouheb L, Dermeche L, Mazari T, Benadji S, Essayem N, Rabia C (2018) Clean adipic acid synthesis from liquid-phase oxidation 
of cyclohexanone and cyclohexanol using $\left(\mathrm{NH}_{4}\right)_{x} \mathrm{~A}_{y} \mathrm{PMo}_{12} \mathrm{O}_{40}(\mathrm{~A}$ : $\mathrm{Sb}, \mathrm{Sn}, \mathrm{Bi}$ ) mixed heteropolysalts and hydrogen peroxide in free solvent. J Catal Lett 148:612-620. https://doi.org/10.1007/s1056 2-017-2263-6

32. Nomiya K, Miwa M, Sugaya Y (1984) Catalysis by heteropolyacid-VII. Catalytic oxidation of cyclohexanol by dodecamolybdate. Polyhedron 3:607-610. https://doi.org/10.1016/S0277 -5387(00)88096-1

33. Penate IQ, Lesage G, Cognet P, Poux M (2012) Clean synthesis of adipic acid from cyclohexene in microemulsions with stearyl dimethyl benzyl ammonium chloride as surfactant: from the laboratory to bench scale. Chem Eng J 200-202:357-364

34. Pérez-Ramırez J, Kapteijn F, Schöffel K, Moulijn JA (2003) Formation and control of $\mathrm{N}_{2} \mathrm{O}$ in nitric acid production: where do we stand today? Appl Catal B Environ 44:117-151. https://doi. org/10.1016/S0926-3373(03)00026-2

35. Piyali B, Kajari G, Safikul I, Astam KP, Manirul I, Asim B (2016) New hybrid iron phosphonate material as an efficient catalyst for the synthesis of adipic acid in air and water. ACS Sustain 4:71477157. https://doi.org/10.1021/acssuschemeng.6b02023

36. Rocchiccioli-Deltcheff C, Fournier M, Franck R, Thouvenot R (1984) Vibrational investigations of polyxometalates. 4. Valence force fields of anions related to the lindqvist structure. J Mol Struct 114:49-56. https://doi.org/10.1016/S0022-2860(84)87202 $-6$

37. Renz M, Blasco T, Corma A, Fornes V, Jensen R, Nemeth L (2002) Selective and shape-selective Baeyer-Villiger oxidations of aromatic aldehydes and cyclic ketones with Sn-beta zeolites and $\mathrm{H}_{2} \mathrm{O}_{2}$. Chem Eur J 8:20

38. Strukul G, Varagnolo A, Pinna F (1997) New (old) hydroxo complexes of platinum(II) as catalysts for the Baeyer-Villiger oxidation of ketones with hydrogen peroxide. J Mol Catal A Chem 17:413-423. https://doi.org/10.1016/S1381-1169(96)00246-4

39. Tahar A, Benadji S, Mazari T, Dermeche L, Marchal-Roch C, Rabia C (2015) Preparation, characterization and reactivity of Keggin type phosphomolybdates, $\mathrm{H}_{3-2 x} \mathrm{Ni}_{x} \mathrm{PMo}_{12} \mathrm{O}_{40}$ and $\left(\mathrm{NH}_{4}\right)_{3-2 x} \mathrm{Ni}_{x} \mathrm{PMo}_{12} \mathrm{O}_{40}$, for adipic acid synthesis. Catal Lett 145:569-575. https://doi.org/10.1007/s10562-014-1373-7

40. Terent'ev AO, Platonov MM, Kashin AS, INikishin GI (2008) Oxidation of cycloalkanones with hydrogen peroxide: an alternative route to the Baeyer-Villiger reaction. Synthesis of dicarboxylic acid esters. Tetrahedron 64:7944-7948. https://doi. org/10.1016/j.tet.2008.06.027

41. Xu S, Wang Z, Zhang X, Zhang X, Ding K (2008) Chiral Brønsted acid catalyzed asymmetric Baeyer-Villiger reaction of 3-substituted cyclobutanones by using aqueous $\mathrm{H}_{2} \mathrm{O}_{2}$. J Angew Chem 120:2882-2885. https://doi.org/10.1002/ange.200705932

Publisher's Note Springer Nature remains neutral with regard to jurisdictional claims in published maps and institutional affiliations. 